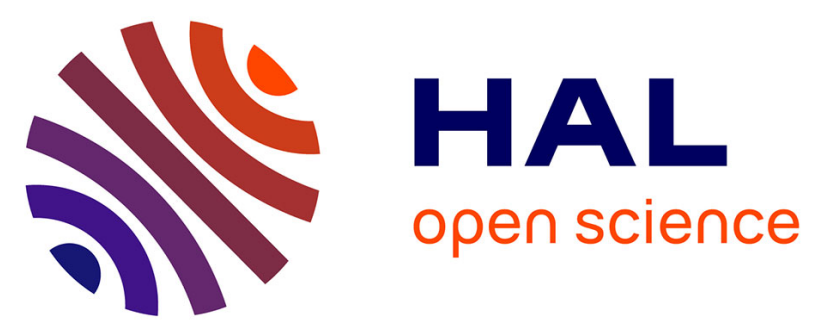

\title{
Poplar Propolis Ethanolic Extract Reduces Body Weight Gain and Glucose Metabolism Disruption in High-Fat Diet-Fed Mice
}

Nicolas Cardinault, Franck Tourniaire, Julien Astier, Charlène Couturier, Estelle Perrin, Julie Dalifard, Eva Seipelt, Lourdes Mounien, Claire Letullier, Lauriane Bonnet, et al.

\section{To cite this version:}

Nicolas Cardinault, Franck Tourniaire, Julien Astier, Charlène Couturier, Estelle Perrin, et al.. Poplar Propolis Ethanolic Extract Reduces Body Weight Gain and Glucose Metabolism Disruption in High-Fat Diet-Fed Mice. Molecular Nutrition and Food Research, 2020, 64 (18), pp.2000275. 10.1002/mnfr.202000275 . hal-03157023

\section{HAL Id: hal-03157023 \\ https://hal.inrae.fr/hal-03157023}

Submitted on 14 May 2021

HAL is a multi-disciplinary open access archive for the deposit and dissemination of scientific research documents, whether they are published or not. The documents may come from teaching and research institutions in France or abroad, or from public or private research centers.
L'archive ouverte pluridisciplinaire HAL, est destinée au dépôt et à la diffusion de documents scientifiques de niveau recherche, publiés ou non, émanant des établissements d'enseignement et de recherche français ou étrangers, des laboratoires publics ou privés. 
1 Poplar propolis ethanolic extract reduces body weight gain and glucose metabolism

2 disruption in high-fat diet-fed mice.

3

4 Nicolas Cardinault $^{3} *$, Franck Tourniaire ${ }^{1,2 *}$, Julien Astier $^{1}$, Charlène Couturier $^{1}$, Estelle Perrin ${ }^{1}$, 5 Julie Dalifard ${ }^{1}$, Eva Seipelt ${ }^{1}$, Lourdes Mounien ${ }^{1}$, Claire Letullier ${ }^{3}$, Lauriane Bonnet ${ }^{1}$, Esma 6 Karkeni $^{1}$, Naïma Delbah ${ }^{4}$, Stéphane Georgé $^{4}$, Jean-François Landrier ${ }^{1,2}$

$8{ }^{1}$ Aix-Marseille Université, C2VN, INRA, INSERM, 13000, Marseille, France

$9{ }^{2}$ CriBioM, Criblage Biologique Marseille, Faculté de médecine de la Timone, Marseille, France.

$10{ }^{3}$ Pollenergie, La Grabère, 47450 Saint Hilaire de Lusignan, France.

$11{ }^{4}$ CTCPA, 449 Avenue Clément Ader, 84911 Avignon.

$12 *$ These authors contributed equally to this work.

14 Running title: Propolis improves obesity and associated disorders

15

16 Corresponding author and person to whom reprint requests should be addressed:

17 Jean-François Landrier, C2VN ; UMR 1260 INRA/1263 INSERM/Université d'Aix-Marseille,

1827 Bd Jean Moulin, 13385 Marseille cedex 05, France. Phone: +33 4912942 75; E-mail: jean-

19 francois.landrier@univ-amu.fr

20

21 Keywords : adipose tissue, insulin resistance, NRF2, obesity, propolis.

22 


\section{Abstract}

24 Scope: Current evidence supports the beneficial effect of polyphenols on the management of

25 obesity and associated comorbidities. This is the case for propolis, a polyphenol-rich substance

26 produced by bees. The aim of the present study was to evaluate the effect of a poplar propolis

27 ethanolic extract (PPEE) on obesity and glucose homeostasis, and to unveil its putative

28 molecular mechanisms of action.

29 Methods and results: Male high-fat (HF) diet-fed mice were administered PPEE for 12 weeks.

30 PPEE supplementation reduced the HF-mediated adiposity index, adipocyte hypertrophy and

31 body weight gain. It also improved HOMA-IR and fasting glucose levels. Gene expression

32 profiling of adipose tissue (AT) showed an induction of mRNA related to lipid catabolism and

33 mitochondrial biogenesis and inhibition of mRNA coding for inflammatory markers.

34 Interestingly, several Nrf2-target genes were induced in AT following administration of PPEE.

35 The ability of PPEE to induce the expression of Nrf2-target genes was studied in adipocytes.

36 PPEE was found to transactivate the Nrf2 response element and the Nrf2 DNA-binding,

37 suggesting that part of the effect of PPEE could be mediated by Nrf2.

38 Conclusion: PPEE supplementation may represent an interesting preventive strategy to tackle 39 the onset of obesity and associated metabolic disorders. 


\section{Introduction}

45 Obesity is a major metabolic risk factor for type 2 diabetes mellitus (T2DM) and a public health 46 problem throughout the world. In T2DM, insulin signaling is progressively lost, leading to an 47 increase in pancreatic insulin production and pancreas exhaustion at the latest stages of the 48 disease [1]. T2DM represents $90-95 \%$ of diabetes mellitus cases worldwide and s a multifactorial 49 disease in which obesity plays a central role [2]. Indeed, obesity generates low-grade 50 inflammation, which is related to the activation of inflammatory pathways (JNK and $\mathrm{NF}_{-\mathrm{K}} \mathrm{B}$ ) in 51 adipose tissue (AT) [3] and increased production of cytokines such as interleukin-6 (IL-6), 52 interleukin-1beta (IL-1 $\beta$ ), tumor necrosis factor alpha (TNF- $\alpha$ ), and chemokines [4] (e.g. 53 monocyte chemotactic protein 1 (MCP-1)) and other mediators of the immune response [3], 54 including microRNA [5-7]. When AT lipid storage capacities are exhausted, ectopic fat depots 55 develop in other tissues, including insulin sensitive tissues (e.g. liver, skeletal muscle). Such 56 ectopic fat accumulation, together with inflammation, interferes with insulin signaling and is 57 central in the development and persistence of insulin resistance[8], observed in T2DM. So far, 58 drug-based therapeutic approaches to tackle obesity and associated disorders remain limited and 59 have either deleterious side effects or poor efficiency. Therefore, alternative "natural" treatments 60 are urgently needed.

61

62 Propolis is a complex natural resinous substance from buds and exudates of selected plant 63 sources, collected by bees, mixed with wax, and transformed in the presence of bee enzymes [9]. 64 Propolis has been used as a folk medicine in many countries since ancient times and has been 65 reported to possess various pharmacological effects such as immunomodulatory, antitumoral, 66 antimicrobial, antiviral, antifungal, anti-inflammatory and antioxidant properties [10]. These 
67 effects are mostly attributed to the nature and amount of phenolic compounds contained in

68 propolis. The chemical composition of propolis is highly dependent upon its plant source(s) and

69 varies with the site of collection [9].

70 Interestingly, several clinical trials have been performed to test the effect of propolis

71 supplementation in T2DM patients [11]. These recently reviewed and meta-analyzed studies

72 suggest that propolis supplementation decreases fasting blood glucose and Hb1Ac levels [11] and

73 indicate that propolis is able to delay or slow down the progression of the disease, and acts by

74 decreasing oxidative stress and inflammatory processes associated with T2DM.

75

76 Preclinical studies have been performed in animal models of obesity and/or diabetes, to 77 investigate the phenotypical impact of propolis supplementation in the diet [12-17]. The 78 molecular mechanisms underlying the observed effects in terms of obesity management and 79 improvement of glucose homeostasis, however, still remain unclear. Thus, the aim of the present 80 study was to evaluate the effect of a standardized poplar propolis ethanolic extract (PPEE) on 81 obesity glucose homeostasis and the physiology of the adipose tissue in high-fat diet-fed mice. 82 The putative molecular mechanisms involved in these effects was also investigated. 


\section{Materials and methods}

\section{Propolis source and extraction}

87 Poplar propolis was collected in the southern regions of France using dietary propolis traps according to special specifications to minimize contamination. It was stored at $-20{ }^{\circ} \mathrm{C}$ prior to extraction. The latter was performed according to a previously published method [18]. Briefly, the propolis sample was cut into small pieces and soaked into $75 \%$ ethanol for 8 days. Following

91 filtration, the filtrate was concentrated under reduced pressure using a rotary evaporator, to 92 afford a poplar propolis ethanolic extract (PPEE). The dry residue was ground to a fine powder 93 by adding food excipients and kindly provided by Pollenergie (Agen, France). The PPEE powder 94 used in this study fully complies with European regulations on food supplements and those more 95 specific of propolis.

97 Total polyphenol content -The total polyphenol content was measured according to the method described by Popova et al.. The results were expressed in $\mathrm{mg} / 100 \mathrm{~g}$ of propolis powder as 99 pinocembrin/galangin equivalent for poplar propolis. Methanolic solutions of pinocembrin/galangin (2/1) were used for calibration purposes [19]. The phenolic profile was 101 determined by HPLC as previously reported. [20]. Briefly, a sample of $1 \mathrm{~g}$ of PPEE powder was 102 dissolved in $30 \mathrm{~mL}$ of ethanol $(70 \%)$ in a $50 \mathrm{~mL}$ Falcon tube then heated for $2 \mathrm{~h}$ at $70{ }^{\circ} \mathrm{C}$. 103 Following centrifugation, the alcoholic phase was recovered and the extraction was repeated 104 twice. The three extracts were combined and adjusted to $100 \mathrm{~mL}$ with $70 \%$ ethanol in a 105 volumetric flask. PP solution was finally diluted 1 to 50 times in methanol / water (1:1). 106 Separation was achieved by HPLC using a Symmetry $\left(250\right.$ x 4.6 mm, $\left.C_{18}\right)$ column (Waters, Saint 
107 Quentin en Yvelines, France). A linear gradient of acetonitrile and $0.2 \%$ aqueous formic acid 108 (v/v) was used as the mobile phase with a flow rate of $1.2 \mathrm{~mL} / \mathrm{min}$ and DAD data were acquired 109 in the 200-450 nm range. Polyphenolic compounds were identified by comparing their retention 110 time and UV characteristics to authentic standards. The total polyphenol content and the detailed 111 composition of polyphenols present in PPEE are reported on Table 1.

113 Animal Experiments - Six-week-old male C57BL/6J mice were obtained from Janvier Labs (Le 114 Genest Saint Isle, France) and fed ad libitum with control food (chow diet A04, Safe-diets, 115 France) and with full access to drinking water for a 1-week acclimatization period. The animals 116 were maintained at $22{ }^{\circ} \mathrm{C}$ under a 12 -h light/dark cycle and a $20 \%$ relative humidity level. The 117 mice ( 3 or 4 per cage) were randomly assigned (10 per group) into one of three experimental 118 groups depending on their diet, i.e.standard (chow diet A04 from Safe diets), high fat (HF: 45\% 119 energy from lipids, Test Diet ref. 58V8) or HF-supplemented with PPEE (20 mg/mouse/day, 120 corresponding to $4.5 \mathrm{mg}$ of total polyphenols/mouse/day). The pellets were replace every 3 121 days. The weight gain was measured once a week and dietary intake was recorded every two 122 weeks. After 12 weeks, the mice were fasted overnight and blood was collected by cardiac 123 puncture using a general anesthetic (sevoflurane, Baxter, France). The plasma was isolated by 124 centrifugation at $3000 \mathrm{rpm}$ for $15 \mathrm{~min}$ at $4{ }^{\circ} \mathrm{C}$ and was stored at $-80{ }^{\circ} \mathrm{C}$ until further analysis. 125 Animals were euthanized by cervical dislocation under general anesthesia, and their tissues 126 (liver and various white AT deposits) were collected, weighted and stored at $-80{ }^{\circ} \mathrm{C}$ until further 127 analysis This protocol was approved by the local Ethics committee and the French Minister of 128 Research and Education ( ${ }^{\circ}$ 01549.04). 
130 Dosage information - The PPEE has been mixed in the food and delivered to mice at the dosage 131 of $20 \mathrm{mg} / \mathrm{mouse} / \mathrm{day}$, which corresponding to $4.5 \mathrm{mg}$ of total polyphenols / mouse / day, for 12

132 weeks. This dosage was chosen to be relevant in human, as it correspond to a dose of $12 \mathrm{mg}$ of 133 total polyphenol / $\mathrm{kg}$ of body weight, taking into account the conversion factor for dose 134 translation between mice and human [21].

Oral glucose and insulin tolerance tests - Glucose and insulin tolerance tests were performed two weeks before animals were euthanized. For the glucose tolerance test, the mice were fasted for16 $\mathrm{h}$ and then gavaged with glucose $(2 \mathrm{~g} / \mathrm{kg})$. For the insulin tolerance test, the mice were fasted for $5 \mathrm{~h}$ and then injected i.p. with insulin $(0.5 \mathrm{U} / \mathrm{kg})$. Blood samples were taken from the tail tips at specific time intervals to measure glucose levels (Accu-Check glucometer, Roche).

142 Biochemical analyses - The concentration of glucose in plasma was evaluated using glucose 143 RTU (bioMerieux, Craponne, France). Triglycerides and free fatty acids (FFA) were measured 144 using a colorimetric test (RANDOX, Crumlin, Co. Antrim, United Kingdom). Insulin was 145 measured using an enzyme-linked immuno-sorbent assay ELISA (ALPCO Diagnostics, New 146 Hampshire, United States). Leptin and adiponectin were quantified by ELISA (R\&D Systems 147 quantikine ELISA). $\beta$-hydroxybutyrate concentration was measured using a colorimetric test 148 according to the manufacturer's procedure (BEN srl, Milano, Italy). The HOMA-IR index was 149 calculated according to the following formula: fasting insulin (microU/L) $\mathrm{x}$ fasting glucose $150 \quad(\mathrm{nmol} / \mathrm{L}) / 22.5$. 
152 Adipose tissue histology - Epididymal AT samples were fixed in $10 \%$ buffered formalin, 153 embedded in paraffin and sliced to prepare $5 \mu \mathrm{m}$ tissue sections that were stained with 154 hematoxylin and eosin (H\&E) as previously reported [22]. The images were captured by a light 155 microscope (EZAD, Leica, Germany). The adipocyte area $\left(\mu \mathrm{m}^{2}\right)$ were determined using the 156 Image J software.

158 Cell culture - 3T3-L1 preadipocytes (ATCC, Manassas, VA) were seeded in 3.5-cm diameter 159 dishes at a density of $15 \times 10^{4}$ cells/well. Cells were grown in DMEM supplemented with $10 \%$ $160 \mathrm{FBS}$ at $37{ }^{\circ} \mathrm{C}$ in a $5 \% \mathrm{CO}_{2}$ humidified atmosphere as previously reported [23]. To induce 161 differentiation, 2-day post-confluent 3T3-L1 preadipocytes (day 0) were stimulated for $48 \mathrm{~h}$ with $1620.5 \mathrm{mM}$ isobutylmethylxanthine, $0.25 \mu \mathrm{M}$ dexamethasone, and $1 \mu \mathrm{g} / \mathrm{mL}$ insulin in DMEM 163 supplemented with $10 \%$ FBS. The cells were maintained in DMEM supplemented with $10 \%$ 164 FBS and $1 \mu \mathrm{g} / \mathrm{mL}$ insulin. To examine the effect of PPEE, 3T3-L1 adipocytes received either 165 PPEE $(3-30 \mu \mathrm{g} / \mathrm{mL})$ or ethanol only $(0.1 \%)$. All treatments were performed on day eight. The 166 data obtained are the mean of three independent experiments, each performed in triplicate.

RNA interference - The 3T3-L1 differentiated cells were seeded in 6-well plates and transfected 169 with either targeted siRNA (against Nrf2) or a non-targeting siRNA according to the 170 manufacturer's instructions (Dharmacon, Inc. Lafayette, CO) and as previously reported [24, 25]. 171 Briefly, the cells were transfected overnight using a mixture of $100 \mathrm{nM}$ siRNA and $2 \mu \mathrm{L}$ of 172 DharmaFECT reagent per well. The media were subsequently replaced with fresh media with or 173 without PPEE and the plates were re-incubated for $24 \mathrm{~h}$. 
175 Reporter assays - The reporter plasmid containing the gene for firefly luciferase under the 176 control of the wild-type or mutated antioxidant response element (ARE) [26] was transfected 177 into 3T3-L1 preadipocyte cells, together with the pGL4 plasmid $(1 \mu \mathrm{g})$ coding for the renilla 178 luciferase. The transfection was performed using Lipofectamine LTX $(0.9 \mu \mathrm{L})($ Thermo, Saint179 Aubin, France) and the Plus Reagent $(1 \mu \mathrm{L})$ as previously reported [27]. After overnight 180 incubation the medium was replaced by DMEM supplemented with $10 \%$ FBS and PPEE (30 $181 \mu \mathrm{g} / \mathrm{mL})$. After $24 \mathrm{~h}$, the cells were lyzed and assayed for luciferase activity using a Dual-Glo 182 luciferase assay system (Promega, Madison, WI) withfirefly luciferase activity normalized to 183 renilla luciferase. The transfection experiments were performed in triplicate and repeated three 184 times independently.

Nfr2 transAM assay - 3T3-L1 cells were incubated for $6 \mathrm{~h}$ with or without PPEE (30 $\mu \mathrm{g} / \mathrm{mL})$.

187 Nuclei were prepared as recommended and used in the TransAM Nrf2 assay according to the 188 manufacturer's protocol (Active Motif; La Hulpe, Belgium)

RNA extraction and real-time PCR - Total RNA was extracted from the liver, kidney and epididymal AT or from cells using TRIzol reagent (Thermo, Courtaboeuf, France). Total RNA (1 $192 \mu \mathrm{g})$ was used to synthetize cDNAs using random primers and Moloney murine leukemia virus reverse transcriptase (Thermo, Courtaboeuf, France). Real-time quantitative PCR analyses were 194 performed using the Mx3005P Real-Time PCR System (Stratagene, La Jolla, USA) as previously 195 described [28]. For each condition, the expression was quantified in duplicate, and 18S rRNA 196 was used as the endogenous control in the comparative cycle threshold (CT) method [29]. 
198 Statistical analysis - All data are expressed as the mean \pm SEM. Significant differences between 199 the control and treated groups were determined using ANOVA, followed by the Tukey-Kramer 200 post hoc test using the Statview software (SAS Institute, Cary, NC). P $<0.05$ was considered 201 statistically significant.

202 


\section{Results}

Poplar propolis ethanolic extract supplementation protects against diet-induced obesity

206 The results showed that PPEE supplementation $(20 \mathrm{mg} / \mathrm{mouse} / \mathrm{day}$, equivalent to $4.5 \mathrm{mg}$ of total 207 polyphenols/mouse/day) significantly limited weight gain $(p<0.0001)$ caused by a HF diet (Fig 208 1A and 1B). The energy intake was higher in the HF diet fed group compared to the control 209 group, but no significant difference $(p<0.002)$ was observed in the PPEE supplemented group 210 compared to the HF diet fed group (Fig 1C). The limitation of body weight gain in PPEE 211 supplemented mice was associated with a reduction of absolute and relative fat mass in 212 epididymal, retroperitoneal or inguinal fat pads (Fig 1D and 1E, $p<0.05$ ). Consequently, the 213 adiposity index (sum of epididymal, inguinal and retroperitoneal AT mass relative to total body 214 mass) in PPEE supplemented mice was reduced, compared to HF diet fed mice (Fig 1F, $215 p<0.001)$. Interestingly no significant difference of adiposity index was observed between PPEE 216 supplemented mice and control fed mice after 12 weeks of supplementation (Fig 1F).

217 Triglycerides, free fatty acids and alanine transaminase (ALAT) were neither affected by the HF 218 diet nor the EEPP supplementation $(p>0.05)$. Adiponectin was not affected by PPEE 219 supplementation compared to the HF diet fed group, but was significantly reduced compared to 220 the control group $(p<0.05)$. The levels of leptin and $\beta$-hydroxybutyrate were increased in the HF 221 diet fed group compared to the control group and were reduced in the PPEE supplemented group $222(p<0.05)($ Table 2$)$. 
225 The effect of PPEE supplementation on glucose homeostasis was evaluated using the oral 226 glucose tolerance test (OGTT) and the insulin tolerance test (ITT). PPEE supplementation 227 improved $(p<0.001)$, glucose tolerance in OGTT (Fig 2A) as highlighted by area under the curve 228 (AUC) of the glycemic response (Fig 2B) which was reduced compared to what is observed in 229 the group of HF fed animals. Additionally, PPEE supplementation reduced blood glucose levels, 230 compared to HF fed mice (Fig 2C and 2D). In fasted conditions, insulinemia and glycaemia that 231 were induced by the HF diet, were normalized in PPEE supplemented mice and were not 232 significantly different from control mice (Fig 2E, $p<0.05$ ). Similarly, the HOMA-IR index was 233 induced $(p<0.005)$ by the HF diet and corrected by PPEE supplementation (Fig $2 \mathrm{~F}$,

Poplar propolis ethanolic extract supplementation changes adipocyte cellularity and modulates gene expression in adipose tissue

237 To evaluate the effect of PPEE supplementation on the phenotype of AT, epidydimal AT was 238 used for histological analysis. A HF diet promoted adipocyte hypertrophy with a significant 239 increase in the adipocyte area compared to the control group. Interestingly, this effect was

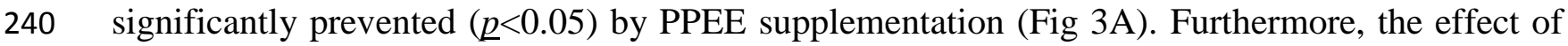
241 PPEE on inflammation in AT was evaluated by measuring the expression of different markers of 242 inflammation including cytokines (Tnfa) and chemokines (Chemokine C-C motif ligand 5 (Ccl5) 243 and $\mathrm{Ccl} 2$ ). As expected, the HF diet induced a strong increase in the mRNA level of these 244 inflammatory markers compared to the control group., PPEE supplementation, on the other hand, 245 caused a significant decrease $(p<0.05)$ of those levels (Fig 3B).

246 To understand the modification of cellularity and fat mass increase, the expression of genes 247 encoding for transcription factors involved in energy metabolism, fatty acid oxidation and 
248 mitochondrial biogenesis were studied. PPEE supplementation stimulated $(p<0.05)$ the 249 expression of genes promoting fatty acid oxidation, such as the peroxisome proliferator activated 250 receptor a (Ppara), the carnitine palmitoyl-transferase 1a (Cpt1a), the medium- and long-chain 251 acyl-CoA dehydrogenases (Mcad and Lcad), and adipose triglyceride lipase (Atgl), compared to

252 HF diet fed mice (Fig 3C). PPEE supplementation also induced $(p<0.05)$ genes related to white 253 AT browning, including genes encoding for the uncoupling protein 1 (Ucp1), the transcription 254 factors peroxisome proliferator-activated receptor gamma coactivator 1-alpha (Ppargc1a), PR 255 domain containing 16 (Prdm16) and cell death-inducing DNA fragmentation factor $\alpha$-like 256 effector A (Cidea) (Fig 3D) as well as the mitochondrial DNA relative content (Fig 3E).

Poplar propolis ethanolic extract supplementation induces the Nrf2 pathway in adipose tissue and adipocytes

260 PPEE contains several polyphenols considered as ligands of the natural nuclear factor (erythroid261 derived 2)-like 2 (Nrf2) [30], and Nrf2 gonists are known to induce a similar metabolic 262 phenotype [31] the activation of this signaling pathway was investigated. PPEE supplementation 263 induced the gene expression of the glutamate-cysteine ligase catalytic subunit (Gclc), glutamate264 cysteine ligase modifier subunit (Gclm), NADPH: quinone oxidoreductase 1 (Nqo1) and heme 265 oxygenase $1($ Hmox 1$)$ in the adipose tissue of mice $(p<0.05)$ (Fig 4A). No effect on Nrf2 gene 266 expression was observed. PPEE $(30 \mu \mathrm{g} / \mathrm{mL})$ significantly $(p<0.05)$ induced the expression of 267 Nrf2, Gclc, Gclm and Nqo1 in 3T3-L1 cells (Fig 4B). The ability of PPEE to transactivate a Nrf2 268 response element (ARE) was confirmed using transient transfection. PPEE increased luciferase 269 activity in 3T3-L1 cells transfected with the wildtype ARE (ARE wt), whereas no induction was 270 observed with the mutated ARE (ARE mut) (Fig 4C, $p<0.05$ ). Furthermore, the increased ability 
271 of Nrf2 to bind to its DNA binding domain in the presence of PPEE was confirmed in 3T3-L1

272 cells (TransAM Nrf2 assay; Fig 4D, $p<0.05$ ). The involvement of Nrf2 in the PPEE-mediated

273 induction of Nrf2, Gclc, Gclm and Nqo1 was confirmed by RNA interference. This PPEE-

274 mediated induction was blunted or abolished in3T3-L1 cells transfected with siRNA against Nrf2

275 compared to control siRNA (Fig. 4E, 4F, 4G and 4H, $p<0.05$ ).

276

277 
In the present study, we reported a beneficial role of PPEE supplementation on weight gain

281 limitation and glucose homeostasis improvement in mice fed a HF diet. In addition, we provided 282 evidences of a direct effect of poplar propolis supplementation on AT biology, strongly 283 suspected to be related to Nfr2 signaling activation in adipocytes.

284 We observed that PPEE supplementation reduced weight gain in mice fed a HF diet. This seems 285 to be mainly related to the limitation of fat mass accumulation as highlighted by a reduced 286 adiposity index. It is noteworthy that these morphological changes were not caused by a reduced 287 energy intake. Interestingly, both subcutaneous (inguinal) and visceral (epididymal and 288 retroperitoneal) adipose pads masses were reduced by PPEE supplementation. The plasma levels 289 of leptin, which is known to be correlated to fat mass, s [32] also decreased. Similar results have 290 been previously observed with Brazilian propolis supplementation, which reduced adiposity and 291 limited the development of perirenal and mesenteric fat depots in high fat-fed rats It was 292 postulated that the anti-obesity effect of propolis correlated to PPAR $\gamma$ inhibition in AT, and 293 reduced triglycerides absorption (after a fat loading test [12].. In mice subjected to a high fat diet, 294 Brazilian propolis also limited body weight gain and visceral AT mass [14], or both epididymal 295 and subcutaneous fat masses. No modification of energy expenditure was observed under 296 propolis supplementation, but an increase of fecal lipids was observed, suggesting that Brazilian 297 propolis reduced intestinal fat absorption [13] The molecular mechanism(s) underlying the effect 298 of propolis on weight gain limitation remains elusive.

299 We studied the cellularity of adipocytes and found that PPEE supplementation could normalize 300 the mean adipocyte area compared to control mice. To explain this effect, we quantified gene 
301 expression linked to lipid metabolism. We observed that PPEE supplementation induced the 302 expression of genes coding for proteins involved in fatty acid oxidative metabolism (Ppar 303 Cpt1, Mcad, Lcad). This suggests that PPEE drove a global fatty acid oxidative program. 304 Previous studies have reported the induction of PPAR $\alpha$, a master regulator of fatty acid 305 oxidation, in the liver of rats supplemented with Brazilian propolis [12]. We also observed a 306 strong induction of genes linked to mitochondria biogenesis and function, such as Ucp1, 307 Ppargcl $\alpha$, Prdm16 and Cidea, and an increase in DNA mitochondrial content with PPEE 308 supplementation. The stimulation of mitochondrial biogenesis and fatty acid oxidative capacity 309 in white adipocytes, when linked to increased energy expenditure in such cells through increased 310 energy uncoupling, via Ucp1 expression and/or waste (e.g., futile cycles), is a potential novel 311 target for the control of obesity and related comorbidities [33], and could explain the PPEE312 induced anti-obesity effect. We, and others, have already proposed a similar mechanism to 313 explain the anti-obesity effect of other molecules,(e.g. trans-retinoic acid) [34].

314 In this study, we also observed a beneficial effect of PPEE on glucose homeostasis. Indeed, 315 PPEE supplementation in our diet induced obesity (DIO) mice model improved fasted glycemia 316 and insulinemia and the HOMA-IR index. An the glucose tolerance and sensitivity to insulin 317 were also improved, but were probably overestimated since doses were not adjusted to total 318 mass [35]. Such observations agree with a recent meta-analysis reporting that propolis 319 administrated to T2DM patients decreased fasting blood glucose and Hb1 Ac levels[11], and with 320 several preclinical studies on the effect of propolis on glucose homeostasis. These studies 321 showed that propolis partly restored glucose tolerance and insulin sensitivity in ob/ob mice [15]. 322 The anti-diabetic effect of propolis has also been described in streptozotocin /high fat diet fed 
323 rodents $[16,17,36]$, where it was found to stop systemic and pancreatic $\beta$-cells inflammation 324 and oxidative stress [17, 37].

325 AT plays a major role in the insulin resistance genesis in the context of obesity, notably through 326 the establishment of a low-grade inflammatory status [3]. The effect of propolis on glucose 327 homeostasis could be due, at least in part, to the impact of PPEE on the inflammation present in 328 AT. When investigating the expression of genes linked to inflammation, we observed that a HF 329 fed diet induced pro-inflammatory cytokines. This was reversed by PPEE supplementation, 330 suggesting that PPEE reduced the inflammatory process in AT. It is presently unclear if such 331 effect is a cell-autonomous effect in adipocytes or if it is related to the reduction of fat mass 332 accumulation, which is associated with an indirect anti-inflammatory effect. This will require 333 further investigations.

334 To further identify the molecular mechanism of action of PPEE we focused on Nrf2. Several 335 compounds found in propolis have been demonstrated to induce the Nrf2 signaling pathway [30], 336 including CAPE [38]. We observed that a large set of Nrf2-target genes were induced in white 337 AT following PPEE supplementation, suggesting that it mediated a strong antioxidant effect in 338 white AT. In addition, we demonstrated a cell-autonomous effect of PPEE supplementation in 339 adipocytes in our in vitro studies. We stimulated the induction of the canonical Nrf2 target genes 340 and demonstrated the specific involvement of Nrf2 using RNA interference. We demonstrated 341 that PPEE transactivated a wild type ARE but not a mutated ARE, and that PPEE induced Nrf2 342 DNA-binding. This demonstrated that PPEE was able to activate the Nrf2 signaling pathway in 343 adipocytes.

344 Nrf2 belongs to the Cap'n collar type transcription factor family (for review [39-41]). In the 345 inactive state, Nrf2 is bound to the protein Keap 1, itself associated with the cytoskeleton, which 
prevents Nrf2 accumulation in the nucleus. The dissociation of Nrf2 and Keap 1 enables nuclear translocation of Nrf2, which binds to ARE after heterodimerisation with the transcription factor Maf. This type of response element is present in many genes encoding antioxidant enzymes: Nqo1, Gclc, Gclm, Hmox-1 and phase II enzymes. In general, molecules capable of inducing Nrf2 will induce the antioxidant system and detoxification system for xenobiotics and other potentially deleterious molecules. The role of $\mathrm{Nrf} 2$ in the control of AT metabolism and adipogenesis has also been extensively studied but remains far from clear [42, 43]. Mice lacking Nrf2 have been found to display either a lean phenotype $[44,45]$ or no protection against obesity $[46,47]$. Nevertheless, if the role of Nrf2 invalidation remains complex, the effect of Nrf2 agonists are clearer and more consensual. Treatment of mice with CDDO-IM fed a HF diet prevented body weight gain possibly through a Nrf2-dependant modulation of hepatic lipid metabolism [48]. Similarly, oltipraz, a well-known Nrf2 inducer [49], as well as glycyrrhizin [50]., blunted the HF-mediated obesity and insulin resistance in mice. Recently, glucoraphanin administration was also found to prevent obesity, insulin resistance and NAFLD in HF fed mice via the Nrf2 pathway [31]. The mechanisms by which Nrf2 activators restore energy homeostasis in DIO mice models remains elusive. Such beneficial effect of Nrf2 inducers could be related to an enhancement of mitochondrial biogenesis and function as reported in several cells types including cardiomyocytes [51] and hippocampus neurons [52]. In addition, Nrf2 activation is well-known to reduce oxidative stress and inflammation, which interfere with energy homeostasis and insulin sensitivity [53, 54]. Nrf2 activation could also improve metabolic disorders induced by a HF diet. Finally, the effect of Nrf2 activation could be related to the induction of lipid catabolism by PPEE in AT, since Nrf2 signaling has already been associated to an induction of lipid oxidation in the liver [55]. All these metabolic pathways are strongly 
369 interconnected and involved in mediating the Nrf2 effects elicited by PPEE. Further work is 370 required to elucidate their relative contribution.

371

372 In conclusion, our results indicate that EEPP protects against HF-mediated obesity by limiting 373 weight gain and regulating glucose homeostasis This is likely to be achieved via interfering with 374 the mitochondrial biogenesis, uncoupling activity, enhancing of lipid oxidation, and limitating 375 oxidative stress and inflammation

376

377

378 


\section{Author contributions}

380 Study design (NC, FT, JFL), data collection (FT, CC, JA, EP, JD, ES, LM, CL, LB, EK, ND), data

381 interpretation (NC, FT, LM, SG, JFL), manuscript preparation (NC, JFL) and funds collection (NC JFL).

382 All the authors have read and approved the final version of this manuscript.

383

384 Acknowledgements

385 This work has been partly funded by INRAE, INSERM and Aix Marseille University and la 386 Région Nouvelle-Aquitaine. We thank Dr. Véronique Seidel for English language editing.

389 Conflict of interest statement

$390 \mathrm{NC}$ and CL are employed by Pollenergie. Other authors have nothing to disclose. 


\section{References}

395

396

397

398

399

400

401

402

403

404

405

406

407

408

409

410

411

412

413

414

415

416

417

418

419

420

421

422

423

424

425

426

427

428

429

430

431

432

433

434

435

[1] Zheng, Y., Ley, S. H., Hu, F. B., Global aetiology and epidemiology of type 2 diabetes mellitus and its complications. Nature Reviews Endocrinology 2017, 14, 88-98.

[2] Riaz, H., Khan, M. S., Siddiqi, T. J., Usman, M. S., Shah, N., Goyal, A., Khan, S. S., Mookadam, F., Krasuski, R. A., Ahmed, H., Association Between Obesity and Cardiovascular Outcomes: A Systematic Review and Meta-analysis of Mendelian Randomization Studies. JAMA Netw Open 2018, 1, e183788.

[3] Gregor, M. F., Hotamisligil, G. S., Inflammatory mechanisms in obesity. Annu Rev Immunol 2011, 29, 415-445.

[4] Tourniaire, F., Romier-Crouzet, B., Lee, J. H., Marcotorchino, J., Gouranton, E., Salles, J., Malezet, C., Astier, J., Darmon, P., Blouin, E., Walrand, S., Ye, J., Landrier, J. F., Chemokine Expression in Inflamed Adipose Tissue Is Mainly Mediated by NF-kappaB. PLoS One 2013, 8, e66515.

[5] Karkeni, E., Astier, J., Tourniaire, F., El Abed, M., Romier, B., Gouranton, E., Wan, L., Borel, P., Salles, J., Walrand, S., Ye, J., Landrier, J. F., Obesity-associated Inflammation Induces microRNA-155 Expression in Adipocytes and Adipose Tissue: Outcome on Adipocyte Function. J Clin Endocrinol Metab 2016, 101, 1615-1626.

[6] Ying, W., Riopel, M., Bandyopadhyay, G., Dong, Y., Birmingham, A., Seo, J. B., Ofrecio, J. M., Wollam, J., Hernandez-Carretero, A., Fu, W., Li, P., Olefsky, J. M., Adipose Tissue Macrophage-Derived Exosomal miRNAs Can Modulate In Vivo and In Vitro Insulin Sensitivity. Cell 2017, 171, 372-384 e312.

[7] Landrier, J.-F., Derghal, A., Mounien, L., MicroRNAs in Obesity and Related Metabolic Disorders. Cells $2019,8,859$.

[8] Olefsky, J. M., Glass, C. K., Macrophages, inflammation, and insulin resistance. Annu Rev Physiol 2010, 72, 219-246.

[9] Sforcin, J. M., Biological Properties and Therapeutic Applications of Propolis. Phytother Res 2016, 30, 894-905.

[10] Pasupuleti, V. R., Sammugam, L., Ramesh, N., Gan, S. H., Honey, Propolis, and Royal Jelly: A Comprehensive Review of Their Biological Actions and Health Benefits. Oxid Med Cell Longev 2017, 2017, 1259510.

[11] Karimian, J., Hadi, A., Pourmasoumi, M., Najafgholizadeh, A., Ghavami, A., The efficacy of propolis on markers of glycemic control in adults with type 2 diabetes mellitus: A systematic review and metaanalysis. Phytother Res 2019, 33, 1616-1626.

[12] Ichi, I., Hori, H., Takashima, Y., Adachi, N., Kataoka, R., Okihara, K., Hashimoto, K., Kojo, S., The beneficial effect of propolis on fat accumulation and lipid metabolism in rats fed a high-fat diet. $J$ Food Sci 2009, 74, H127-131.

[13] Sakai, T., Ohhata, M., Fujii, M., Oda, S., Kusaka, Y., Matsumoto, M., Nakamoto, A., Taki, T., Nakamoto, M., Shuto, E., Brazilian Green Propolis Promotes Weight Loss and Reduces Fat Accumulation in C57BL/6 Mice Fed A High-Fat Diet. Biol Pharm Bull 2017, 40, 391-395.

[14] Koya-Miyata, S., Arai, N., Mizote, A., Taniguchi, Y., Ushio, S., Iwaki, K., Fukuda, S., Propolis prevents diet-induced hyperlipidemia and mitigates weight gain in diet-induced obesity in mice. Biol Pharm Bull 2009, 32, 2022-2028.

[15] Kitamura, H., Naoe, Y., Kimura, S., Miyamoto, T., Okamoto, S., Toda, C., Shimamoto, Y., Iwanaga, T., Miyoshi, I., Beneficial effects of Brazilian propolis on type 2 diabetes in ob/ob mice: Possible involvement of immune cells in mesenteric adipose tissue. Adipocyte 2013, 2, 227-236. 
[16] Peng, S., Wei, P., Lu, Q., Liu, R., Ding, Y., Zhang, J., Beneficial Effects of Poplar Buds on Hyperglycemia, Dyslipidemia, Oxidative Stress, and Inflammation in Streptozotocin-Induced Type-2 Diabetes. J Immunol Res 2018, 2018, 7245956.

[17] Chen, L. H., Chien, Y. W., Chang, M. L., Hou, C. C., Chan, C. H., Tang, H. W., Huang, H. Y., Taiwanese Green Propolis Ethanol Extract Delays the Progression of Type 2 Diabetes Mellitus in Rats Treated with Streptozotocin/High-Fat Diet. Nutrients 2018, 10.

[18] Kosalec, I., Bakmaz, M., Pepeljnjak, S., Vladimir-Knezevic, S., Quantitative analysis of the flavonoids in raw propolis from northern Croatia. Acta Pharm 2004, 54, 65-72.

[19] Popova, M., Bankova, V., Butovska, D., Petkov, V., Nikolova-Damyanova, B., Sabatini, A. G., Marcazzan, G. L., Bogdanov, S., Validated methods for the quantification of biologically active constituents of poplar-type propolis. Phytochem Anal 2004, 15, 235-240.

[20] Gardana, C., Scaglianti, M., Pietta, P., Simonetti, P., Analysis of the polyphenolic fraction of propolis from different sources by liquid chromatography-tandem mass spectrometry. J Pharm Biomed Anal 2007, 45, 390-399.

[21] Reagan-Shaw, S., Nihal, M., Ahmad, N., Dose translation from animal to human studies revisited. FASEB J 2008, 22, 659-661.

[22] Fenni, S., Hammou, H., Astier, J., Bonnet, L., Karkeni, E., Couturier, C., Tourniaire, F., Landrier, J. F., Lycopene and tomato powder supplementation similarly inhibit high-fat diet induced obesity, inflammatory response, and associated metabolic disorders. Mol Nutr Food Res 2017.

[23] Karkeni, E., Marcotorchino, J., Tourniaire, F., Astier, J., Peiretti, F., Darmon, P., Landrier, J. F., Vitamin $D$ limits chemokine expression in adipocytes and macrophage migration in vitro and in male mice. Endocrinology 2015, 156, 1782-1793.

[24] Karkeni, E., Bonnet, L., Astier, J., Couturier, C., Dalifard, J., Tourniaire, F., Landrier, J. F., All-transretinoic acid represses chemokine expression in adipocytes and adipose tissue by inhibiting NF-kappaB signaling. J Nutr Biochem 2017, 42, 101-107.

[25] Bonnet, L., Karkeni, E., Couturier, C., Astier, J., Dalifard, J., Defoort, C., Svilar, L., Martin, J. C., Tourniaire, F., Landrier, J. F., Gene Expression Pattern in Response to Cholecalciferol Supplementation Highlights Cubilin as a Major Protein of 25(OH)D Uptake in Adipocytes and Male Mice White Adipose Tissue. Endocrinology 2018, 159, 957-966.

[26] Liu, Y., Kern, J. T., Walker, J. R., Johnson, J. A., Schultz, P. G., Luesch, H., A genomic screen for activators of the antioxidant response element. Proc Natl Acad Sci U S A 2007, 104, 5205-5210.

[27] Fenni, S., Astier, J., Bonnet, L., Karkeni, E., Gouranton, E., Mounien, L., Couturier, C., Tourniaire, F., Bohm, V., Hammou, H., Landrier, J. F., (all-E)- and (5Z)-Lycopene Display Similar Biological Effects on Adipocytes. Mol Nutr Food Res 2019, 63, e1800788.

[28] Bonnet, L., Hachemi, M. A., Karkeni, E., Couturier, C., Astier, J., Defoort, C., Svilar, L., Martin, J. C., Tourniaire, F., Landrier, J. F., Diet induced obesity modifies vitamin D metabolism and adipose tissue storage in mice. J Steroid Biochem Mol Biol 2019, 185, 39-46.

[29] Livak, K. J., Schmittgen, T. D., Analysis of relative gene expression data using real-time quantitative PCR and the 2(-Delta Delta C(T)) Method. Methods 2001, 25, 402-408.

[30] Matzinger, M., Fischhuber, K., Heiss, E. H., Activation of Nrf2 signaling by natural products-can it alleviate diabetes? Biotechnol Adv 2018, 36, 1738-1767.

[31] Nagata, N., Xu, L., Kohno, S., Ushida, Y., Aoki, Y., Umeda, R., Fuke, N., Zhuge, F., Ni, Y., Nagashimada, M., Takahashi, C., Suganuma, H., Kaneko, S., Ota, T., Glucoraphanin Ameliorates Obesity and Insulin Resistance Through Adipose Tissue Browning and Reduction of Metabolic Endotoxemia in Mice. Diabetes 2017, 66, 1222-1236.

[32] Coppari, R., Bjorbaek, C., Leptin revisited: its mechanism of action and potential for treating diabetes. Nat Rev Drug Discov 2012, 11, 692-708. 
[33] Flachs, P., Rossmeisl, M., Kuda, O., Kopecky, J., Stimulation of mitochondrial oxidative capacity in white fat independent of UCP1: a key to lean phenotype. Biochim Biophys Acta 2013, 1831, 986-1003. [34] Tourniaire, F., Musinovic, H., Gouranton, E., Astier, J., Marcotorchino, J., Arreguin, A., Bernot, D., Palou, A., Bonet, M. L., Ribot, J., Landrier, J. F., All-trans retinoic acid induces oxidative phosphorylation and mitochondria biogenesis in adipocytes. J Lipid Res 2016, 56, 1100-1109.

[35] McGuinness, O. P., Ayala, J. E., Laughlin, M. R., Wasserman, D. H., NIH experiment in centralized mouse phenotyping: the Vanderbilt experience and recommendations for evaluating glucose homeostasis in the mouse. American Journal of Physiology-Endocrinology and Metabolism 2009, 297, E849-E855.

[36] Li, Y., Chen, M., Xuan, H., Hu, F., Effects of encapsulated propolis on blood glycemic control, lipid metabolism, and insulin resistance in type 2 diabetes mellitus rats. Evid Based Complement Alternat Med 2012, 2012, 981896.

[37] Nna, V. U., Abu Bakar, A. B., Md Lazin, M., Mohamed, M., Antioxidant, anti-inflammatory and synergistic anti-hyperglycemic effects of Malaysian propolis and metformin in streptozotocin-induced diabetic rats. Food Chem Toxicol 2018, 120, 305-320.

[38] Stahli, A., Maheen, C. U., Strauss, F. J., Eick, S., Sculean, A., Gruber, R., Caffeic acid phenethyl ester protects against oxidative stress and dampens inflammation via heme oxygenase 1. Int J Oral Sci 2019, 11,6 .

[39] Nguyen, T., Yang, C. S., Pickett, C. B., The pathways and molecular mechanisms regulating Nrf2 activation in response to chemical stress. Free Radic Biol Med 2004, 37, 433-441.

[40] Owuor, E. D., Kong, A. N., Antioxidants and oxidants regulated signal transduction pathways. Biochem Pharmacol 2002, 64, 765-770.

[41] Nair, S., Li, W., Kong, A. N., Natural dietary anti-cancer chemopreventive compounds: redoxmediated differential signaling mechanisms in cytoprotection of normal cells versus cytotoxicity in tumor cells. Acta Pharmacol Sin 2007, 28, 459-472.

508

509 regulating energy metabolism. J Nutr Biochem 2012, 23, 1201-1206.

[43] Seo, H. A., Lee, I. K., The role of Nrf2: adipocyte differentiation, obesity, and insulin resistance. Oxid Med Cell Longev 2013, 2013, 184598.

[44] Pi, J., Leung, L., Xue, P., Wang, W., Hou, Y., Liu, D., Yehuda-Shnaidman, E., Lee, C., Lau, J., Kurtz, T. W., Chan, J. Y., Deficiency in the nuclear factor E2-related factor-2 transcription factor results in impaired adipogenesis and protects against diet-induced obesity. J Biol Chem 2010, 285, 9292-9300.

[45] Chartoumpekis, D. V., Ziros, P. G., Psyrogiannis, A. I., Papavassiliou, A. G., Kyriazopoulou, V. E., Sykiotis, G. P., Habeos, I. G., Nrf2 represses FGF21 during long-term high-fat diet-induced obesity in mice. Diabetes 2011, 60, 2465-2473.

[46] Zhang, Y. K., Wu, K. C., Liu, J., Klaassen, C. D., Nrf2 deficiency improves glucose tolerance in mice fed a high-fat diet. Toxicol Appl Pharmacol 2012, 264, 305-314.

[47] Collins, A. R., Gupte, A. A., Ji, R., Ramirez, M. R., Minze, L. J., Liu, J. Z., Arredondo, M., Ren, Y., Deng, T., Wang, J., Lyon, C. J., Hsueh, W. A., Myeloid deletion of nuclear factor erythroid 2-related factor 2 increases atherosclerosis and liver injury. Arterioscler Thromb Vasc Biol 2012, 32, 2839-2846.

[48] Shin, S., Wakabayashi, J., Yates, M. S., Wakabayashi, N., Dolan, P. M., Aja, S., Liby, K. T., Sporn, M. B., Yamamoto, M., Kensler, T. W., Role of Nrf2 in prevention of high-fat diet-induced obesity by synthetic triterpenoid CDDO-imidazolide. Eur J Pharmacol 2009, 620, 138-144.

[49] Yu, Z., Shao, W., Chiang, Y., Foltz, W., Zhang, Z., Ling, W., Fantus, I. G., Jin, T., Oltipraz upregulates the nuclear factor (erythroid-derived 2)-like 2 [corrected](NRF2) antioxidant system and prevents insulin resistance and obesity induced by a high-fat diet in C57BL/6J mice. Diabetologia 2011, 54, 922-934.

530 fat diet-induced obesity in rats by activating NrF2 pathway. Life Sci 2018, 193, 159-170. 
531 [51] Piantadosi, C. A., Carraway, M. S., Babiker, A., Suliman, H. B., Heme oxygenase-1 regulates cardiac 532 mitochondrial biogenesis via Nrf2-mediated transcriptional control of nuclear respiratory factor-1. Circ 533 Res 2008, 103, 1232-1240.

534 [52] Hota, K. B., Hota, S. K., Chaurasia, O. P., Singh, S. B., Acetyl-L-carnitine-mediated neuroprotection 535 during hypoxia is attributed to ERK1/2-Nrf2-regulated mitochondrial biosynthesis. Hippocampus 2012, $536 \quad 22,723-736$.

537 [53] Furukawa, S., Fujita, T., Shimabukuro, M., Iwaki, M., Yamada, Y., Nakajima, Y., Nakayama, O., 538 Makishima, M., Matsuda, M., Shimomura, I., Increased oxidative stress in obesity and its impact on 539 metabolic syndrome. J Clin Invest 2004, 114, 1752-1761.

540 [54] Houstis, N., Rosen, E. D., Lander, E. S., Reactive oxygen species have a causal role in multiple forms 541 of insulin resistance. Nature 2006, 440, 944-948.

542 [55] Tanaka, Y., Aleksunes, L. M., Yeager, R. L., Gyamfi, M. A., Esterly, N., Guo, G. L., Klaassen, C. D., NF543 E2-related factor 2 inhibits lipid accumulation and oxidative stress in mice fed a high-fat diet. J 544 Pharmacol Exp Ther 2008, 325, 655-664.

545

546

547 
obesity. A. Body weight evolution was quantified for each mouse ( $n=10$ per group). B. Before sacrifice, animal weight was recorded. C. Energy intake was quantified by measuring food intake (absolute organ weight / body weight). F. Adiposity index was calculated by dividing the sum of adipose tissues weight by the body weight of animal. Values are presented as means \pm SEM. Bars not sharing the same letter were significantly different in Tukey-Kramer post hoc test $\mathrm{p}<$ $5560,05$.

Fig 2. Poplar propolis ethanolic extract improves glucose homeostasis. A. Glucose levels during the oral glucose tolerance test (OGTT; $n=10$ mice per group). B. Area under the curve (AUC) for the glycemic response during OGTT. C. Glycemia evolution during the insulin tolerance test (ITT; $\mathrm{n}=10$ mice per group).

D. Area under the curve for the glycemic response mean values. Values are presented as means \pm SEM. Bars not sharing the same letter were significantly different in Tukey-Kramer post hoc test $\mathrm{p}<0,05$.

Fig 3. Poplar propolis ethanolic extract effect on adipocyte cellularity, gene expression and DNA mitochondrial content in adipose tissue. A. Representative histological images of epididymal fat pads H\&E stained, taken at 10X magnification. Adipocyte area determined using

B. Relative expression of epididymal adipose tissue genes related to 
570 inflammatory markers measured through qPCR and expressed relative to $18 \mathrm{~S}$ ribosomal RNA.

571 C. Relative expression of epididymal adipose tissue genes related to lipid metabolism measured

572 through qPCR and expressed relative to $18 \mathrm{~S}$ ribosomal RNA. D. Relative expression of 573 epididymal adipose tissue genes related to mitochondrial metabolism measured through qPCR 574 and expressed relative to $18 \mathrm{~S}$ ribosomal RNA. E. Mitochondrial DNA quantification in 575 epididymal adipose tissue. Mitochondrial DNA to nuclear DNA ratio was determined by qPCR. $576 \mathrm{~N}=10$ mice per each group, values are presented as means \pm SEM. Bars not sharing the same 577 letter were significantly different in Tukey-Kramer post hoc test $\mathrm{p}<0,05$.

Fig 4. Poplar propolis ethanolic extract induces Nrf2 pathway in adipose tissue and adipocytes. A. Relative expression of epididymal adipose tissue Nrf2-target genes coding for 581 antioxidant enzymes measured through qPCR and expressed relative to $18 \mathrm{~S}$ ribosomal RNA 582 (n=10 mice per group). B. 3T3-L1 adipocytes were incubated with growing concentrations of 583 PPEE for $24 \mathrm{~h}$. Expression of Nrf2-target genes coding for antioxidant enzymes measured 584 through qPCR and expressed relative to 18S ribosomal RNA. C. 3T3-L1 adipocytes were 585 transiently transfected with plasmid containing wild-type or mutated antioxidant response 586 element (ARE) and cells were incubated for $24 \mathrm{~h}$ with $30 \mu \mathrm{g} / \mathrm{ml}$ of PPEE. Luminescence was 587 monitored and standardized. D. 3T3-L1 adipocytes were incubated with PPEE 30 $\mu \mathrm{g} / \mathrm{ml}$ ) for 24 588 h. DNA binding activity was monitored using transAM Nrf2 assay. E to H. 3T3-L1 adipocytes 589 were transiently transfected with non-targeted (NT) siRNA or siRNA directed against Nrf2 for 590 24h. cells were incubated for an additional 24h, and gene expression was quantified by qPCR 591 and expressed relative to $18 \mathrm{~S}$ ribosomal RNA. Values are presented as means \pm SEM of 3 
592 independent cultures per treatment condition. Bars not sharing the same letter were significantly 593 different in Tukey-Kramer post hoc test $\mathrm{p}<0,05$.

594

595

596

597

598 